\title{
doispontos:
}

\section{O Isso e a determinação inconsciente das doenças orgânicas: a contribuição de Georg W. Groddeck à psicanálise}

\author{
Georgina Faneco Maniakas \\ Universidade Federal de São Carlos
}

\begin{abstract}
Resumo: $O$ ano de 2016 marca os 150 anos de nascimento de Georg Walther Groddeck, primeiro médico a utilizar o referencial psicanalítico para o tratamento das doenças orgânicas. Groddeck se tornou mais conhecido no meio psicanalítico devido a sua contribuição para a formulação freudiana da segunda tópica por meio do conceito de Isso (Id). Freud reconhece sua contribuição em O Eu e o Isso de 1923, e admite em carta a Pfister que Groddeck provavelmente estaria certo em relação às determinações inconscientes das doenças orgânicas. Entretanto, para Groddeck, o seu Isso, herdeiro do Deus-Natureza de Goethe, não se poderia restringir aos limites a ele atribuídos por Freud na formulação de sua segunda representação tópica do aparelho psíquico. Anterior à formação da unidade biopsíquica do sujeito, o Isso de Groddeck, uma espécie de matriz de onde emana toda a existência somatopsíquica, determinaria tanto a saúde quanto a doença, a vida e a morte.
\end{abstract}

Palavras-chave: Groddeck; Isso; psicossomática; psicanálise; Freud; símbolo.

Abstract: 2016 celebrates the 150th anniversary of the birth of Georg Walther Groddeck, first physician to use the psychoanalytic approach to the treatment of organic diseases. Groddeck became better known in the psychoanalytic circle due to his contribution to the formulation of Freud's Second Topic, through the concept of It (Id). Freud recognizes his contribution in The Ego and the Id (1923), and admits in a letter to Pfister that Groddeck was probably right in relation to the unconscious determinations of organic diseases. However, for Groddeck his It, heir of Goethe's God-Nature, it can not be restricted to the limits assigned to it by Freud in his second topographical representation of the psychic apparatus. Previous to the constitution of biopsychic unity of the individual, the It of Groddeck, a kind of matrix from which emanates all the somatopsychic existence, would determine both the health and sickness, the life and death.

Keywords: Groddeck; It; psychosomatic; psychoanalysis; Freud; symbol.

"A vida do Isso... emana de um tempo aquém da lembrança” Georg Groddeck (1923).

Quando inicia sua correspondência com Freud, em 1917, Georg Groddeck já havia publicado uma série de artigos sobre doenças orgânicas. Nesse mesmo ano publica Determinações psíquicas e tratamento psicanalítico das afecções orgânicas. Em contato com a psicanálise desde 1913, nesse meio-tempo veio a descobrir, por si próprio, a importância dos símbolos e do inconsciente - o que chamou de Isso, tanto na determinação de doenças psíquicas como de doenças orgânicas. Em sua primeira carta a Freud, Groddeck refere ter descoberto a psicanálise por meio das afecções orgânicas. 
Como meio de expressão do Isso inconsciente, a doença possui múltiplas determinações. Ela pode desempenhar o papel de defesa e externalizar reações como a febre, a inflamação, a diarreia. Ela pode surgir como um meio necessário para que o organismo mantenha seu equilíbrio; neste sentido, Groddeck nos fornece um exemplo a partir do resfriado comum. Que é o resfriado senão uma tentativa de cura, de recuperação do equilíbrio perdido, por meio de um esforço do organismo para livrar as mucosas de substâncias nocivas?

Como, para o autor, saúde e doença não são mutuamente excludentes, a doença também pode ser reconhecida em sua dimensão positiva, como um meio de proteção. "O Isso do ser humano se distende, leva-o ao cansaço e à fadiga, e, em parte para desculpá-lo do fracasso, em parte para ganhar tempo e reunir novas forças, faz com que ele fique doente" (GRODDECK 1917/1992, p. 12).

Se todas as doenças provêm do inconsciente, não há o menor sentido em demarcar o território do psíquico ou somático, nem há sentido na expressão psicogênese, pois todas as doenças são, concomitantemente, psicogênicas e fisiogênicas. A única justificativa para a expressão "estados nervosos", segundo o autor, é a ignorância sobre a qual se alicerçava a medicina da época, que não conseguia estabelecer nexos satisfatórios entre processos químicos, fisiológicos, biológicos e nervosos.

Para Groddeck, a razão jamais poderá expressar conceitualmente a grandeza incomensurável do que denomina Isso, já que o Isso, como a tudo o mais, a antecede. Em suas palavras: "[o Isso] ri escondido. Porque ele sabe: este órgão (o cérebro), que eu criei por minha reflexão, imaginará logo poder refletir sozinho, independentemente; entretanto, ele não passa de um instrumento, uma espécie de joguete que eu, o Isso, criei para mim” (D’ÈPINAY, 1988, p 143, n 7).

Herdeiro do Deus-Natureza de Goethe, o Isso é uma totalidade, que se pode manifestar por meio do inconsciente ou do consciente, do corpo ou da psique, do psicológico ou do fisiológico.

Para o autor, é a partir de um recorte dessa totalidade que Freud constrói seu conceito de Isso. Porém, a distância entre este e o conceito original parece ser tão acentuada, que Groddeck não reconhece no Isso freudiano o seu Isso. No início de um de seus artigos, $O$ trabalho do sonho e do sintoma orgânico, ele adverte:

Em seu livro, O Eu e o Isso (Das Ich und das Es), Freud me concedeu a honra de me indicar como sendo a primeira pessoa a empregar a expressão Isso (das Es) e afirmar que iria assumi-la. É verdade, mas só que o conceito de Isso, como eu o utilizava para as minhas finalidades, não servia para Freud e, consequentemente, ele o transformou em outra coisa diferente do que eu concebi (GRODDECK, 1926 / 1992, p. 161).

Segundo o autor, Freud teria conformado o Isso a uma instância do aparelho psíquico, e, dessa forma, realizado uma "domesticação" inconcebível. É com uma visível irritação em relação a Freud que, em 15 de maio de 1923, Groddeck escreve à esposa:

[...] seu Isso é de uso limitado somente para a compreensão das neuroses. Ele arrisca-se de um modo muito furtivo no reino das doenças orgânicas, com a ajuda de um instinto de morte ou pulsão de destruição, tomadas de Stekel ou de Spielrein. Ele desconsidera o aspecto construtivo de meu Isso... (GRODDECK, 1977, p. 13).

Para Groddeck, o Isso nunca poderá ser totalmente apreendido como conceito por ser a própria matriz da qual emana toda a existência somato-psíquica.

Esse Isso dota sua criatura, a personalidade e o ego de um ser humano, de nariz, boca, músculos, ossos, cérebro, faz com que esses órgãos funcionem e entrem em atividade já antes do nascimento, e impele o ser que está surgindo a ações convenientes, antes de completar-se o desenvolvimento de seu cérebro (GRODDECK, 1920/1992, p. 130). 
Para o autor, a realidade, em si mesma, não é física nem psíquica, de modo que somático e psíquico só podem ser pensados como atributos por meio dos quais o inconsciente, o Isso incognoscível, é percebido pela consciência. Por isso, quando Freud evoca essa potência incomensurável para dar conta do polo pulsional do aparelho, acreditando poder proceder à sua "domesticação" ao encaixá-la em um sistema regido pela lógica dicotômica entre soma e psique, ele subestima o aspecto simbólico e inominável implícito nesse conceito.

Para Groddeck, o Isso é o poder que comanda toda a vida do ser humano, cuja maior parte é inacessível: "[...] nosso cérebro e, com ele, nossa razão são uma criação do Isso... O Isso do ser humano "pensa" antes do cérebro existir; pensa sem cérebro, ele constrói o cérebro" (GRODDECK, 1923/1986, p.209 /1926, p. 267).

O Isso desconhece o tempo das coisas, ele é a nossa própria vida. "O ser humano é vivido pelo Isso", diria. Ele está em constante movimento, fluindo, refluindo, rejeitando para a superfície ora um pedaço do mundo, ora aquele. O Isso também pode rejeitar conteúdos. Nesse sentido, Groddeck aborda a repressão como um processo normal, existente em todos os organismos, e que, ao incidir sobre um conteúdo psíquico, desencadeia uma cascata de reações orgânicas.

Como parte do funcionamento normal, Groddeck concebe a repressão a partir de um raciocínio muito simples: ao sermos capazes de ver, ouvir, cheirar, provar, tocar, é porque fomos capazes de reprimir um enorme contingente de estímulos que chegam aos sentidos, selecionando apenas pequenas frações deles.

Como o ato de pensar está intimamente associado a todo o funcionamento orgânico, ao esforço de repressão de um pensamento segue-se uma contração dos músculos abdominais, e de outros grupos musculares, resultando em uma perturbação na circulação sanguínea. Através do grande simpático, outros setores do organismo são afetados, começando pelos mais próximos do abdômen: estômago, intestinos, fígado, coração, órgãos respiratórios. Tal perturbação, por menor que seja, desencadeia toda uma série de processos químicos. Dada a frequência do processo de repressão, e dependendo da intensidade e duração da tensão, tem-se uma noção das relações entre esses dois modos de expressão (psíquico ou orgânico). Por isso, diz não se surpreender com o fato de que a repressão - ou qualquer outro fenômeno psíquico provoca problemas orgânicos. (GRODDECK, 1923/1986, p.151 /1926, p. 145).

Entretanto, a produção de manifestações somáticas não está restrita ao mecanismo de repressão, embora o autor lhe atribua um papel de destaque como desencadeador de enfermidades. Seu posicionamento desafia a psicanálise a buscar o significado oculto na doença orgânica, ao invés de se restringir ao tratamento das neuroses.

Em 27 de maio de 1923, inconformado, ele dirige uma dura carta a Freud, como resposta à publicação de O Eu e o Isso (1923). Nesta, o autor compara-se a um arado, e Freud, ao camponês que o manipula:

Ele (o arado) ainda não entende porque o fazendeiro insiste em arar primeiro o solo pedregoso; o arado não gosta de entrar no solo do Ego, onde a distinção entre psicológico e físico é demais pronunciada. (...) Eu tenho a impressão de que, por alguma razão, o fazendeiro permanece na região da assim chamada psique, pelo menos por enquanto, e talvez possa arruinar um sem número de arados sem produzir uma grande colheita (GRODDECK, 1977, p. 80).

Nessa carta, Groddeck confessa ter interrompido um artigo por causa da angústia do "arado", que não sabe quais são as intenções do "fazendeiro". Em seguida, utilizando mais uma metáfora, diz: "eu temo que o solo destrua as sementes e permita o crescimento de ervas daninhas" (GRODDECK, 1977, p. 79). 
Somente em 18 de junho de 1925 Freud tocará novamente no assunto com Groddeck para dizer que, embora o seu Isso derive do de Groddeck, ele não reconhece no Isso de Groddeck o seu Isso, "civilizado, burguês e desmistificado" (GRODDECK, 1977, p. 93).

Em carta datada de 9 de setembro de 1927, Groddeck defende o aspecto mítico de seu Isso, comenta saber que Freud não aprecia o seu Livro d'Isso, o que pode influenciar a acolhida de sua obra. Na oportunidade, desfere outro ataque, dessa vez ao que entende ser obras inexpressivas e repetitivas produzidas pela comunidade psicanalítica. Groddeck não termina esta carta sem antes interpretar o silêncio de Freud em relação a ele, com as seguintes palavras: "Groddeck tem uma ideia útil, mas eu - Freud - não posso aprovar o modo como ele a coloca; ele deve e terá que se virar sozinho" (GRODDECK, 1977, p. 98). ${ }^{1}$

Freud não responde, e a correspondência entre ambos fica interrompida por um longo período. É Anna Freud quem escreve a Groddeck, quase dois anos depois, para dar notícias de seu pai. A partir de então, a correspondência entre ele e Freud é retomada, mas seguem-se apenas mais seis cartas até a morte de Groddeck, em 1934.

Apesar da dificuldade relacional entre ambos, ${ }^{2}$ Freud não deixa de reconhecer a aplicabilidade que Groddeck faz da psicanálise às doenças orgânicas. Pouco depois da publicação de $O$ livro d'Isso, Freud confessa a Oskar Pfister: "Para quatro quintos dos casos, Groddeck tem, certamente, razão em atribuir ao Isso as doenças orgânicas e pode ser que esteja no caminho certo também para o último quinto que resta" (GRODDECK, 1977, p. 106, n. 79).

É com ênfase que, em uma de suas últimas cartas a Freud, em 3 de fevereiro de 1932, Groddeck defende a conexão entre o símbolo e a vida, e a influência do símbolo sobre o organismo todo e, individualmente, sobre cada uma de suas partes. É por meio do símbolo, meio-termo entre o si mesmo e a doença, que o indivíduo pode se reconciliar com o que lhe é estranho. Groddeck considera o sintoma como o que não está integrado, com o inconcebível pelo sujeito, sendo que o sofrimento só cessará quando o sujeito acessar e integrar a si esse conteúdo.

Groddeck defende a ideia de que somente uma pulsão interior à simbolização (GRODDECK, 1922/1992, p. 90-1) pode explicar, em última instância, a configuração das representações simbólicas. Em um artigo de 1922, intitulado A pulsão à simbolização, o autor supõe, através de uma alusão à construção das habitações, que a ideia de casa, por exemplo, não surge de forma aleatória, mas é configurada a partir de uma pulsão interior à simbolização, cuja referência simbólica é o útero fecundado. (O mesmo se dando com outros animais que constroem sua morada.). Desse modo, Groddeck remete ao próprio corpo o significado originário das ideias e das palavras, obscurecido, posteriormente, por tantas outras associações.

O autor caracteriza o sintoma orgânico como um fenômeno apartado de seu significado simbólico, que está à mercê de um movimento ilimitado de substituições, escorregando de um significado a outro, podendo significar tudo e qualquer coisa, e o compara às formações léxicas esquizofrênicas, nas quais "o Isso se comporta como se não levasse em conta a etimologia; apega-se, como um grego inculto, aos sons da palavra e as utiliza para provocar a doença e alimentá-la” (GRODDECK, 1923/1986, p. 95-6/1926, p. 118).

Para Groddeck, a tarefa do terapeuta, diante desse quadro, é a de promover a "liga" com o simbólico. E Groddeck a executa despojando-se de sua própria pessoa, para permitir que o Isso - fonte do simbólico se expresse por meio de um discurso e ritmo próprio. Nesse sentido, a palavra é eficaz na medida em que, ao promover o acesso ao simbólico, revela uma ordem oculta e realiza mudanças nessa ordem. Entretanto, não nos devemos deixar seduzir pela eficácia da palavra, pois, para Groddeck, ela é apenas um dos meios de acesso ao simbólico. 
O homem desvenda-se simbolicamente, e essa simbolização não provém do pensamento racional, mas de processos desconhecidos do Isso. O inconsciente é o lugar dos símbolos. Diz: "O Isso - o inconsciente - pensa através de símbolos" (GRODDECK, 1923/1986, p. 41/1926, p. 51).

Desse modo, o ser humano está irremediavelmente submetido à atividade simbolizadora do inconsciente. Como o símbolo precede toda existência e convenções humanas, este nunca poderá ser totalmente desvendado e elucidado pela linguagem. É do Isso que emana toda a ideia e representação. Para o autor (GRODDECK, 1923 / 1986, p. 45/ 1926, p. 55) os símbolos: “[...] não são invenções; eles existem, fazem parte dos bens inalienáveis do homem; pode-se mesmo dizer que todo pensamento e toda a ação consciente são consequência inevitável da simbolização inconsciente, que o ser humano é vivido pelo símbolo".

Assim, a função de simbolização seria a mais primária das funções do Isso, tal como se mover, enxergar etc. A existência insere-se, portanto, em um quadro mais amplo, preestabelecido, de natureza simbólica. O símbolo a tudo engloba.

A própria linguagem surge associada a sensações somáticas, nos primórdios vivenciadas como experiências conscientes, posteriormente desfiguradas pela repressão e pela modulação dos afetos. A liga original entre corpo, afeto e linguagem remete-nos à suposição de uma matriz simbólica, da qual derivaria uma "linguagem matricial", da qual emergem diversas modalidades expressivas, dentre as quais a linguagem verbal. Talvez por isso Freud tenha sustentado que o simbolismo não é algo restrito aos sonhos, mas que, por estar presente em diversas formas de expressão cultural, se fossem empreendidas investigações mais aprofundadas, poder-se-ia se chegar à conclusão de que os povos constroem sua linguagem sobre os mesmos símbolos.

O que Groddeck defende é que, se acreditamos estar na presença do signo de uma doença real, é porque o caráter simbólico desse signo está perdido para a consciência, mas não para o inconsciente. $\mathrm{O}$ desafio é formular uma interpretação que permita ao sujeito recuperar o sentido daquilo que, em uma alteração somática, permanece inconsciente, como material "extralinguístico".

Em Ferenczi (1932/1992, p. 271), encontramos a ideia de que em uma época em que ainda não existia o pré-consciente, mas apenas reações emocionais (prazer/desprazer) no corpo, os eventos "psíquicos" (aspas do autor) teriam deixado seus traços mnêmicos na linguagem corporal, sob a forma do que chamou de mnemos orgânicos-psíquicos, incompreensíveis ao nosso consciente.

Um dos caminhos para a interpretação desse material parece aproximar-se do tratamento dado por Freud ao material onírico. Assim como o sonho contém uma multiplicidade de elementos, para Groddeck o mesmo se dá com a afecção somática, produto da intersecção entre elementos somáticos e psíquicos. Em seu artigo de 1926, O trabalho do sonho e do sintoma orgânico, Groddeck defende a interpretação das alterações somáticas como as dos sonhos. Compara os modos de funcionamento do símbolo, tanto no sonho como no sintoma orgânico, e a articulação entre eles (que dá lugar a um processo dinâmico, a figuração simbólica), por meio da qual o sintoma orgânico, ou o "sonho corporal” (expressão de R. Lewinter), pode ser analisado (D'EPINAY, 1988, p. 91).

Nessa mesma direção, na seção II de Reflexões sobre o trauma (1932-34/1992), Ferenczi fornece um exemplo clínico no qual corpo e sonho estão fundidos em uma só unidade. Uma de suas pacientes, durante sua hora de sono mais profundo, acordava repetidamente com o sentimento de grande agitação, com uma espécie de reminiscência "abafada" de sensações dolorosas de um sonho sem conteúdo psíquico, onde ela experimentava um sofrimento de natureza corporal e psíquica, com "esboços de sensações" nos diferentes órgãos. Em um novo mergulho no sono, surgiam diante de si imagens oníricas muito vivas, 
distorções e atenuações dos eventos vividos no primeiro sonho, mas sem qualquer possibilidade de representação dos conteúdos repetitivos, vividos de forma puramente emocional/corporal (FERENCZI, 1932-34/1992, pp. 112-13).

Tais conteúdos, que, em Princípios de relaxamento e neocatarse (1929-30), são atribuídos, por Ferenczi, a uma regressão a estágios do desenvolvimento em que "não estando o órgão do pensamento completamente formado, só eram registradas as lembranças físicas" (FERENCZI, 1929-30 / 1992, p. 65), só se tornam acessíveis à análise mediante certas modificações na técnica. ${ }^{3}$

A proposta terapêutica ferencziana para a abordagem do material corporal (que inclui as técnicas de relaxamento e neocatarse) certamente tem em Groddeck sua fonte de inspiração, pois é por meio da massagem que este autor aborda o material extralinguístico.

O objetivo da massagem, segundo Groddeck, é servir como apoio ao tratamento analítico, além de liberar diretamente a "força de cura imanente ao organismo" (GRODDECK, 1931/1992, p. 194), possibilitando ao paciente compreender que estar enfermo é um processo e não um estado imutável, "um processo orgânico vital e não algo constante e sem vida" (GRODDECK, 1931/1992, p. 193). Ela intensifica o trânsito entre os materiais inconscientes e conscientes, que se apresentam ora de forma psíquica, ora de forma somática. A respiração é um bom exemplo desse trânsito, pois, segundo Groddeck, ela "utiliza e libera uma massa incrível de energia psíquica” (GRODDECK, 1931/ 1992, p. 195), o que pode ser percebido por qualquer um que retiver a respiração até não suportar mais.

Groddeck observa que, logo nos primeiros toques, o doente entende que o seu diagnóstico envolve uma infinidade de coisas, muito mais importantes para a sua recuperação do que o diagnóstico em si, mera palavra utilizável em suas fantasias.

A concepção que o autor tem do corpo como um espaço vital, animado pela circulação de correntes de energia, impede que se considerem os sintomas somáticos como epifenômenos assimbólicos, que utilizam a materialidade corpórea para uma descarga carente de significado.

Para Groddeck, os próprios órgãos do corpo são simbólicos.

Nesse quadro de referência, a questão da eleição de órgão - um dos fatores essenciais para a compreensão das doenças somáticas, segundo Henry Ey (s/d) - se justifica, o que contrasta com a incógnita que essa questão representa para as teorias psicossomáticas que se apoiam na ideia de uma descarga que não possui sentido, por estar privada de ligação psíquica. A questão da escolha de órgão contrasta com a ideia de que os sujeitos que somatizam somente atuam, ao invés de simbolizarem.

"Cada parte do corpo forma símbolos específicos", afirma Byington (1988, p. 29), e cada um "dos cinco aparelhos ou sistemas corporais (respiratório, digestivo, cardiovascular, neuroendócrino e locomotor) afeta de forma característica um sem-número de símbolos que estruturam tipicamente nossa identidade e nossa forma de estar no e conhecer o mundo".

Para este autor, são os aspectos do corpo simbólico que estruturam a consciência, dotando-lhe de forma e limites. Ele nos diz: "O corpo é a batuta da orquestra que expressa a vida dentro da finitude. (...) Seu papel na expressão dos dois acordes extremos da vida, o nascimento e a morte, por si só dão à dimensão do corpo importância central na delimitação da consciência" (BYINGTON, 1988, p. 29).

Para nascer é preciso ter um corpo, para morrer é preciso abandonar o corpo. O corpo, portanto, é o indivíduo enquanto processo, não enquanto "coisa". Assim como a natureza e a palavra, o corpo é parte de um universo simbólico, que a tudo abrange e conecta. Para Groddeck, cada coisa está indissoluvelmente 
ligada ao todo, e o todo, presente em cada parte da realidade; a relação entre os símbolos e os referentes aos quais aludem não é arbitrária, mas fundamenta-se em uma unidade de sentido que apenas pode ser conjeturada, pois está perdida para a consciência e para a linguagem. Embora a linguagem humana, em sua essência gramatical, possa ser entendida como uma das estruturas mais complicadas do universo cujo surgimento deve remontar a certas etapas de complexidade biológica durante o desenvolvimento evolutivo -, Groddeck a considera muito limitada para comunicar o que há de mais profundo na natureza humana. Ele nos diz que a linguagem mente, distorce, viola fatos, nos faz olhar o mundo por uma falsa perspectiva, e, sendo imprecisa, faz-nos pensar falsamente. Em relação à possibilidade da linguagem expressar a verdade, o autor responde parafraseando os evangelhos: "A verdade não está nem no céu, nem na terra, nem entre o céu e a terra" (GRODDECK, 1912/1977, p. 251).

Em um artigo de 1912, "Linguagem" (revisto e reeditado posteriormente entre seus escritos psicanalíticos), apesar de Groddeck admitir a dependência da linguagem para expressarmos as coisas do mundo, afirma que ela falha em comunicar o essencial. Defende que os mais recônditos pensamentos humanos, as forças inconscientes e criativas, o entrecruzamento de sentimentos, impressões, pensamentos, lembranças e seus fragmentos, que chamamos de conteúdos afetivos, e os esquemas em constante movimento, não conseguem expressar-se por meio da linguagem. Para ele "a Vida é um abismo de escuridão impenetrável, do qual emergem estranhas formas como borboletas, as quais perdem sua beleza quando os dedos as tocam; o mesmo se dá com nossos pensamentos quando eles têm que ser colocados em palavras" (GRODDECK, 1912/1977, p. 249).

Ao questionar a validade dos enunciados próprios da linguagem para expressar as manifestações simbólicas do Isso, incluindo as afecções somáticas, Groddeck leva-nos a considerar: (1) que uma semântica deveria aproximar-se do universo dos símbolos, em seu sentido mais amplo, sem restringir-se ao domínio exclusivo da linguagem; (2) que a comunicação, como a define Bateson, ${ }^{4}$ representa um sistema dinâmico que funciona em laços, em voltas, que nunca podem ser entendidos através da lógica linear; (3) que a elucidação de determinado fenômeno não se pode dar dentro de um sistema no qual ele se insere como elemento, por esse estar limitado em e determinado por seu próprio nível de linguagem; e por fim, mas não menos importante, (4) que uma hipótese abrangente para a compreensão das alterações somáticas não pode ser formulada dentro de um sistema regido por uma lógica dicotômica entre soma-psique, uma vez que toda solução que não transcenda o nível de linguagem inerente a um determinado sistema tende a operar de forma recorrente dentro do próprio sistema.

Se a compreensão da afecção somática requer a consideração de uma dimensão extralinguística de simbolização, sua apreensão também requer formulações que transcendam o sistema no qual a doença somática é concebida como expressão assimbólica de um corpo mudo, reduzido à simples materialidade.

Somente quando o ego - fruto da ilusão ("não há eu”, enfatiza Groddeck em 1912/1977, p. 254) - for sobrepujado por meio de um salto para fora do sistema de referência que ele criou para si, é que se pode dar o acesso da consciência a outro nível de percepção da realidade, infinitamente mais rico e complexo.

Tal e qual uma grade de coordenadas espaciais, a matriz groddeckiana (das Es), da qual emanam os símbolos, permanece ao fundo, produzindo efeitos em e por meio de nossos sistemas de referências, e muito além dele, em cada uma, e em todas as coisas do mundo.

Nesse sentido, a aventura proposta por Groddeck talvez possa ser expressa por meio de uma analogia com o zen: na tentativa de compreender mais profundamente o que é, salta-se sempre mais e mais para fora do que se percebe ser, por meio da quebra de toda regra e convenção a que se percebe ligado - inclusive as do próprio zen. É em algum ponto desse caminho impalpável que, talvez, se dê a iluminação, 
e, com ela, a sensação de integração com todo o universo - ou, em Groddeck, com a matriz da qual tudo emana: o Isso.

\section{REFERÊNCIAS BIBLIOGRÁFICAS}

GRODDECK, Georg W. (1912/1977). Language. In: The meaning of illness. Select Psychoanalitic Writings by Georg Groddeck including his correspondence with Sigmund Freud. New York: International Universities Press, 1977, p. 248-264.

(1917-34/1977). Correspondence with Sigmund Freud. In: The meaning of illness. New York: International Universities Press, 1977, p. 31-108

(1917/1992). Condicionamento psíquico e tratamento das moléstias orgânicas pela psicanálise. In: Estudos psicanalíticos sobre psicossomática. São Paulo: Editora Perspectiva, 1992, p. 09-28.

(1920/1992). Sobre o Isso. In: Estudos psicanaliticos sobre psicossomática. São Paulo: Editora Perspectiva, 1992, p. 29-51.

(1922/1992). A pulsão à simbolização. In: Estudos psicanalíticos sobre psicossomática. São Paulo: Editora Perspectiva, 1992, p. 83-95.

(1923/1926). Das Buch vom Es. Leipzig: Internationaler Psychoanalytisher

Verlag, 1926.

(1923/1984). O livro d'Isso. São Paulo: Perspectiva, 1984.

(1925/1992). O sentido da doença. In: Estudos psicanalíticos sobre psicossomática. São Paulo: Editora Perspectiva, 1992, p. 97-102.

(1925/1992). O Isso e a Psicanálise, além de considerações gerais sobre os congressos científicos de outrora, bem como da atualidade. In: Estudos psicanalíticos sobre psicossomática. São Paulo: Editora Perspectiva, 1992, p. 113-123.

(1925/1992). A ambivalência a serviço da transferência e da resistência. In: Estudos psicanalíticos sobre psicossomática. São Paulo: Editora Perspectiva, 1992, p. 107-111.

(1926/1992a). Sobre o absurdo da psicogênese. In: Estudos psicanalíticos sobre psicossomática. São Paulo: Editora Perspectiva, 1992, p. 125-26.

(1926/1992b). O trabalho do sonho e do sintoma orgânico. In: Estudos psicanalíticos sobre psicossomática. São Paulo: Editora Perspectiva, 1992, p. 159-166.

(1928/1992). Sobre os princípios da psicoterapia. In: Estudos psicanalíticos sobre psicossomática. São Paulo: Editora Perspectiva, 1992, p. 173-181. 
(1931/1992). A massagem. In: Estudos psicanalíticos sobre psicossomática. São Paulo: Editora Perspectiva, 1992, p. 191-195.

(1932/1992). Da visão, do mundo dos olhos e da visão sem os olhos. In: Estudos psicanalíticos sobre psicossomática. São Paulo: Editora Perspectiva, 1992, p. 203-252.

(1933a/1992). "Eu me resfrio”. In: Estudos psicanalíticos sobre psicossomática. São Paulo: Editora Perspectiva, 1992, p. 253-55.

(1933b/1992). Da barriga e sua alma. In: Estudos psicanalíticos sobre psicossomática. São Paulo: Editora Perspectiva, 1992, p. 257-289.

\section{OUTROS AUTORES}

BATESON, Gregory (1972). Steps to an ecology of mind. Northvale: Jason Aronson, 1972. (1980). Mind and nature: a necessary unity. Toronto: Bantam Books, 1980

BYINGTON, Carlos A. B. (1988). Dimensões simbólicas da personalidade. São Paulo: Editora Ática, 1988. D’EPINAY, M. P. (1988). Groddeck: a doença como linguagem. Campinas: Papirus, 1988.

EY, Henry; BERNARD, P.; BRISSET, C. Manual de Psiquiatria. 5. edição revisada. Rio de Janeiro: Editoras Masson \& Atheneu (s/d).

FALZEDER, Ernst; BRABANT, Eva (2000). The correspondence of Sigmund Freud and Sándor Ferenczi. Vol. 3, 1920-1933. (Introduction by Judith Dupont.) The Belknap Press of Harvard University Press: Cambridge, Massachussets; London, England, 2000.

FERENCZI, S. (1929-30/1992). Princípios de relaxamento e neocatarse. In: Obras completas de Sandór Ferenczi. Psicanálise IV. (Introdução de Michael Balint.) Martins Fontes, 1992, p. 53-68.

FERENCZI, S. (1932-34). Reflexões sobre o trauma. In: Obras completas de Sandór Ferenczi. Psicanálise IV. (Introdução de Michael Balint) Martins Fontes, 1992, pp. 109-17.

(1932/1992). Notas e Fragmentos. In: Obras completas de Sandór Ferenczi. Psicanálise IV. (Introdução de Michael Balint) Martins Fontes, 1992, p. 271.

FREUD, S. O eu e o Isso (1923/1992). In: Obras Completas de S. Freud, vol. 19. Buenos Aires: Amorrortu Editores, 1992, p. 01-66.

HOFSTADTER, Douglas R. (2001). Gödel, Escher, Bach: um entrelaçamento de gênios brilhantes. Brasília: Editora Universidade de Brasília, São Paulo: Imprensa Oficial do Estado, 2001. 


\section{NOTAS}

1. Em carta enviada por Freud a Ferenczi, em dezembro de 1925, encontramos a confirmação dos sentimentos de Groddeck nas seguintes palavras de Freud: "Pessoalmente, eu gosto muito dele, mas cientificamente ele provavelmente não é utilizável; ele se sobrecarrega com a influência da psicanálise sobre o orgânico e com o Isso, e ele não é o homem certo para desenvolver uma ideia”. In: The correspondence of Sigmund Freud and Sándor Ferenczi, vol. III, 1920-1933, p. 238.

2. Na correspondência entre os autores, nota-se a ambivalência com que Freud recebia as inovações de Groddeck. Além das dificuldades inerentes à relação entre ambos (pois, segundo Schacht, 1977, apesar de Groddeck considerar-se discípulo de Freud, ele não fazia a sua parte), a importância atribuída por Groddeck aos símbolos -fundamentais a compreensão das desordens somáticas - e também aos mitos estaria evocando em Freud a lembrança das ideias de Jung, com quem travou uma intensa relação, rompida por questões dificilmente justificáveis apenas por seus aspectos racionais?

3. Essas modificações teriam sido, em parte, responsáveis pelo abalo final entre Freud e Ferenczi, em agosto de 1932, segundo versão deste último. (In: The Correspondence of Sigmund Freud and Sandor Ferenczi, vol. III, p. 442-43, n. I.)

4. Gregory Bateson (1904-1980), biólogo e antropólogo, contemporâneo de Vigotski e de Bahktin, dedicou-se ao estudo da psiquiatria, psicologia, sociologia, comunicação e ecologia. É considerado um dos pioneiros da perspectiva ecossistêmica dos processos de vida. Interessado pelos paradoxos da comunicação, em 1952 funda o grupo Palo Alto, que em 1956 publicou a conhecida teoria do "duplo vínculo" como uma causa possível da esquizofrenia. 